\title{
Life with limb instead limb for life-selective perfusion safes extremities
}

\author{
Martin Czerny, MD, MBA
}

\author{
From the University Heart Center Freiburg-Bad Krozingen, Freiburg, Germany. \\ Disclosures: Author has nothing to disclose with regard to commercial support. \\ Received for publication Feb 21, 2018; accepted for publication Feb 22, 2018; available ahead of print March 20, \\ 2018. \\ Address for reprints: Martin Czerny, MD, MBA, University Heart Center Freiburg-Bad Krozingen, Albert Lud- \\ wigs University Freiburg Faculty of Medicine, Südring 15, Freiburg 79189, Germany (E-mail: martin.czerny@ \\ universitaets-herzzentrum.de). \\ J Thorac Cardiovasc Surg 2018;156:171 \\ $0022-5223 / \$ 36.00$ \\ Copyright (c) 2018 by The American Association for Thoracic Surgery \\ https://doi.org/10.1016/j.jtcvs.2018.02.063
}

The need for any kind of extracorporeal life support (ECLS) or venoarterial extracorporeal membrane oxygenation per se creates an already challenging scenario for patients affected, and outcome is highly dependent on the underlying pathology, the way the problem can be solved, and the potential of recovery according to the collateral injury that has occurred. ${ }^{1,2}$

However, when ECLS is necessary, several details have to be taken into consideration to deliver the entire benefit of the therapy. One major determinant of success or failure is reestablishing or maintaining limb perfusion. Many unsuccessful ECLS runs are due to primary or secondary lower-extremity malperfusion and its early or late consequences. ${ }^{3}$ The primary approach for inserting cannulas has been surgical cut-down, which still should be considered as a pragmatic treatment option in many cases. However, especially in the case of continuing resuscitation measures parallel to surgical exposure, this can be challenging. Still, as soon as systemic flow is established, the insertion of an additional limb perfusion cannula can be done without taking additional steps.

As techniques develop, the threshold to insert cannulas via ultrasound-guided puncture has decreased, and this approach is increasingly used in the acute scenario. Two important details remain to be considered. The first one is the issue of primarily using a preclosure technique because the benefit of percutaneous access is equalized when it comes to the need of cannula removal without having used this approach. The second one is that puncture of the limb perfusion cannula has to be done before the central cannulas are inserted because otherwise access is difficult.

The current report shares a further conceptual development taking distal perfusion to the next level by using a crossover technique, which is frequently used when treating obliterative lesions in peripheral arterial occlusive disease.

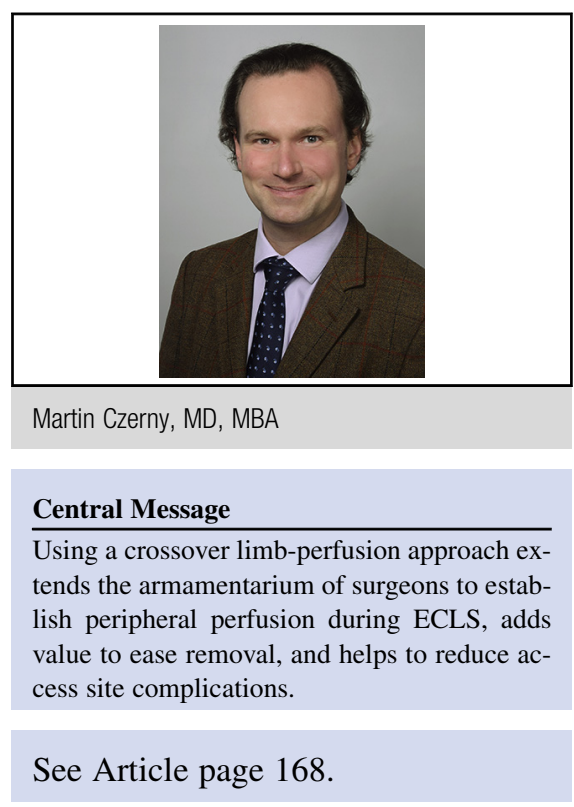

The beauty of the approach is that nonobstructive access is provided because both groins are used, provided that iliac artery diameter is sufficient to host both cannulas. In addition, the remaining risk of vessel occlusion during removal is low as opposed to an ipsilateral distal superficial femoral puncture. Contralateral percutaneous closure of the limb perfusion insertion site can be done with a plug-based closure device. One should not forget to evaluate whether, at the level where both cannulas are side by side, stasis is present and a thrombus may develop.

This reports extends the armamentarium of surgeons to establish peripheral perfusion during ECLS, adds value to ease the removal, and helps to reduce access site complications.

\section{References}

1. Ghodsizad A, Lai CM, Grant AA, Mendoza C, Loebe M, Koerner M, et al Endovascular crossover perfusion of lower limb in patients supported on venoarterial extracorporeal membrane oxygenation: rescue therapy or thoughtful approach. J Thorac Cardiovasc Surg. 2018;156:168-70.

2. Kreibich M, Czerny M, Benk C, Beyersdorf F, Rylski B, Trummer G. Thigh compartment syndrome during extracorporeal life support. J Vasc Surg Venous Lymphat Disord. 2017;5:859-63.

3. Zimpfer D, Heinisch B, Czerny M, Hoelzenbein T, Taghavi S, Wolner E, et al. Late vascular complications after extracorporeal membrane oxygenation support. Ann Thorac Surg. 2006;81:892-5. 